\title{
Constraints analysis in adoption of best farm practices towards sequestration of greenhouse gases
}

\author{
Rati Mukteshawar and P. S. Seharawat* \\ Department of Extension Education, CCS Haryana Agricultural University, Hisar - 125001, INDIA \\ *Corresponding author. E-mail: psshehrawat1965@gmail.com \\ Received: November 13, 2014; Revised received: October 5, 2015; Accepted: January 25, 2016
}

\begin{abstract}
The aim of this paper is to find out the major losses due to emission of green house gases (GHGs) and investigate the major constraints that are responsible for non-adoption of best farming practices to minimize the emission of GHG in agricultural sectors in Haryana state. The study was conducted in two districts of Haryana state namely; Hisar and Karnal. A total number of 120 farmers were interviewed to analyze the constraints in adoption of best farm practices towards sequestration of GHGs and losses occurred. The study resulted that very serious losses occurred due to greenhouse gases were found crop benefit ratio decreased with mean score of 1.23 , crop damaged due to adverse climatic uncertainty (1.07), crop production decreased (0.89), sowing season changed (0.86), loss in bio-diversity (0.84), less income earned from agriculture (0.81), soil water holding capacity decreased (0.68). The other serious losses perceived due to emission of GHGs were deeper level of ground water table (0.31), cropping pattern and cropping system changed (0.28), high usages of inorganic fertilizers (0.23), soil fertility decreases (0.13). While the constraints that were found responsible in non-adoption of best farming practices towards sequestration of GHGs were noticed as non- availability of package of practices $(96.11 \%)$, lack of awareness about health risk in humans $(94.72 \%)$, no reward for adoption of environmental measures $(93.05 \%)$, lack of demonstration/ training for reducing GHG emission $(91.11 \%)$, less credibility in farm practices $(90 \%)$ were major problems observed in adoption of farm practices.
\end{abstract}

Keywords: Best practices, Constraints, Losses, Sequestration of greenhouse gases

\section{INTRODUCTION}

Agriculture has been an important profession for Indian people since the early ages, still about $60 \%$ of the Indian population depends on agriculture for their livelihood. The world's population has grown at an alarming rate with a corresponding increase in demand for natural resources, energy, food and goods. The exploding populations in recent years burdened on agriculture heavily, therefore, to meet the consumption needs, farmers have to really depend upon the inorganic fertilizers. No doubt, these inorganic fertilizers have increased the production of almost all the crops on one hand, but harmful effects have also been reported on the other hand. Apart from this, chemical based intensive agricultural practices are contributing significantly for the production of GHG and thus degrade the environment (IPCC, 2001; Aggarwal, 2003).

As a consequence of increase in consumption, vast quantities of gases and effluents are discharged that may change the climate composition of the atmosphere and its capacity to regulate its temperature. The rise in the global temperature is caused by the accumulation of these GHGs namely, Carbon dioxide $\left(\mathrm{CO}_{2}\right)$, Methane $\left(\mathrm{CH}_{4}\right)$, Nitrous oxide $\left(\mathrm{N}_{2} \mathrm{O}\right)$ and Chlorofluorocarbon (IPCC, 2001).
All three of the major GHGs, Carbon dioxide $\left(\mathrm{CO}_{2}\right)$, Methane $\left(\mathrm{CH}_{4}\right)$, and Nitrous oxide $\left(\mathrm{N}_{2} \mathrm{O}\right)$ are components of the earth's natural cycling of carbon and nitrogen. Agricultural lands, because of their large extent and intensive management, have a significant impact on the earth's carbon and nitrogen cycles, and agricultural activities result in releases of all three of these GHGs are the collective chemicals that make up the earth's atmosphere that help keep the temperature of the earth's surface relatively constant (IPCC, 2006).

The major losses reveled from study were farmers' experiences high uses of chemical inputs to control the pest and diseases attack on the crop but they found less control on them and the amount of application of chemical inputs increases season after season. Farmers noticed that the ground water table goes down due to low rainfall. Farmers also experiences degradation of forest land into barren lands, soil productivity decreases, more soil erosion and soil salinity increases. Farmers also found total crop loss due to adverse climate condition that's why farmers want to quitting the agriculture profession. The income from the agriculture decreases day by day. Now at present agriculture is very risky profession (Sinha et al., 1998, Ladha et al., 2003).

Most of the farmers could not understand the objective 
of sequestration of GHG for better agricultural practices because they were lacking in proper training and demonstration about farm practices and alternative measures which help to sequestration of GHG or decreases the level of GHG emissions. Farmers are still confused in between responsible factors for environment degradation due to lack of awareness about environmental degradation. Farmers also encountered problems regarding less availability of organic farms inputs, lack of linkage between various organizations and lack of collective action for sequestration of GHG for sustainable agriculture and for better development in agriculture. Such types of problems encountered by the farmers are help to fill the gap and find the way to mitigate the GHG problems in agriculture. Due to lacking farmers can not able to adopt the farm practices (Anonymous, 2010).

Keeping in view, the present investigation was conducted to study the constraints analysis in adoption of best farm practices towards sequestration greenhouse gases.

\section{MATERIALS AND METHODS}

The present study was conducted in Haryana state. Two districts Hisar and Karnal were selected, purposively, because multiple cropping systems are practiced in these districts. A total number of eight villages were selected, randomly then from each village, 15 farmers were selected, randomly. Hence, a total number of 120 farmers were interviewed.

An inventory was developed containing 22 statements pertaining possible losses to measure the awareness about the losses due to GHG emission. The respondents were asked in closed ended questions to reply as very serious, serious and not so serious and weightages were given to their responses category were 3,2 and 1, respectively. Aggregate total score was calculated for each cause separately, and based upon this total score obtained, a mean score for each loss was calculated for assessing the seriousness of losses.

On the other hand, after judging the responses of all the respondents for obtaining losses on a three point continuum rating scale, the total score for losses was worked out and this total score was converted into weighted mean score. Finally, a ' $Z$ ' score was obtained for judging the seriousness of each loss contained in the schedule by using the formula as under:

Z score $=\frac{X-\bar{X}}{S D}$

To find out the probable constraints in non-adoption of farm practices that hinder the adoption of farm practices to sequestration of GHG to farmers, an inventory of constraints was prepared based on available literature, personal experience, and discussion with the agricultural experts and farmers.

A list of constraints was prepared and farmers were asked to speak out their responses against each constraint, whether it was very serious, serious and not so serious. Weightage given to their corresponding responses category were 3, 2 and 1, respectively. Aggregate total score were calculated for all constraint separately, and on the basis of calculated score, a weighted mean score for each constraint was obtained and was ranked according to the maximum or minimum mean scores for assessing the seriousness of constraints. The maximum mean score percentage so obtained was given the rank $1^{\text {st }}$ and the next subsequent one was given $2^{\text {nd }}$ and so on the descending orders.

\section{RESULTS AND DISCUSSION}

Farmers' perception regarding losses occurred due to emission of GHG: The Table 1 revealed that the crop benefit ratio decrease ( $Z$ score 1.23 ) and crop damage due to adverse climatic uncertainty ( $Z$ score 1.07$)$ were considered as very serious losses in agriculture due to emission of GHG by the respondents as per the ' $Z$ ' score. The data revealed that crop production decreased $(Z$ score 0.89 ) followed by sowing season changed ( $Z$ score 0.86 ), loss in bio-diversity ( $Z$ score 0.84$)$, less income from agriculture ( $Z$ score 0.81 ) were found serious losses as per $Z$ score perceived by the respondents. Climatic changes will have negative effects on agricultural production in parts of Asia, and especially on resource-poor farmers, the sector also presents opportunities for emission reductions. Warming across the Asian continent will be unevenly distributed, but will certainly lead to crop yield losses in much of the region and subsequent impacts on prices, trade, and food security (Rosegrant et. al. 2010).

It is obvious from the table 2 that soil water holding capacity decreased ( $Z$ score 0.68 ), deeper level of ground water table ( $Z$ score 0.31$)$, cropping pattern and cropping system changed ( $Z$ score 0.28 ), high usages of synthetic or inorganic fertilizers $(Z$ score 0.23$)$, 'soil fertility decreases ( $Z$ score 0.13 ) and degradation of forests to barren lands ( $Z$ score 0.10$)$, soil erosion' ( $Z$ score 0.07 ), and cropping intensity decreased ( $Z$ score $0.00)$ were also serious losses in nature according to the respondents' responses.

The Table 2 showed that Change of land for housing/ industrial usage/SEZ (Z score - 0.02), quality deterioration of crop produce ( $Z$ score - 0.07 ), crop loss due to flood and drought $(Z$ score - 0.13) and quitting agriculture leads unemployment $(Z$ score - 0.18 ) were perceived serious loss in agriculture due to low production by the respondents. It was also found that desertification due to prolonged drought $(Z$ score -0.47$)$ and reduction in soil carbon stocks ( $Z$ score - 0.86) was found serious losses. The Inter-Governmental Panel on Climate Change has shown that the earth temperature has increased by 0.74 degrees C between 1906 and 2005 due to the increase in anthropogenic emissions of greenhouse gases. By the end of this century, temperature increase is likely to be 1.8-4.0 degrees C. This would lead to more frequent hot extremes, floods, droughts, cyclones and gradual recession of glaciers, which in turn 
would result in greater instability in food production. It is estimated that crop production loss in India by $2100 \mathrm{AD}$ could be $10-40 \%$ despite the beneficial effects of higher $\mathrm{CO} 2$ on crop growth. We could lose 4-5 million tonnes of wheat with every rise of 1 degrees $\mathrm{C}$ temperature (Aggarwal, 2008).

Due to emission of GHGs farmers found losses in their crop production and they also shifted their cropping pattern due to uncertainty of climate conditions. Environmental temperature have been raising that because of GHGs emission and affecting the crop cycle.

Crop mature earlier because of high temperature and sometime late mature due to low temperature. Cropping season changed due to GHG emission. Soil temperature affects the rate of organic matter decomposition and release of nutrients. At high temperature, though nutrient availability will increase in the short term, in long run organic matter content will diminish resulting in decline in soil fertility (Katyal, 2000).

On the same lines, Aggarwal (2008) in their crop simulation study have estimated that under the situation of doubling of carbon dioxide in the atmosphere the wheat yields could decrease by 28 to 68 per cent without considering the carbon dioxide fertilization effects. Yield of $\mathrm{C}_{3}$ crops like wheat, barley, rice, and potatoes may increase by $30 \%$ due to $\mathrm{CO}_{2}$ fertilization (Attri and Rathore, 2003) and (Aggarwal et al., 2003) of Indian Agriculture Research Institute, New Delhi.

Farmers' experiences high uses of chemical inputs to control the pest and diseases attack on the crop but they found less control on them and the amount of application of chemical inputs increases season after season. Farmers noticed that the ground water table goes down due to low rainfall and farmers did not aware about the GHG emission and climate change is responsible for low rainfall. Farmers also experiences degradation of forest land into barren lands, soil productivity decreases, more soil erosion and soil salinity increases and crop loss due to adverse climate condition perhaps the major reason that farmers are quitting the agriculture. The income from the agriculture decreases day by day and now agriculture has becoming a risky profession.

Similar threats were also quoted by Ramaraj et al. (2009) that in tropical countries even moderate warming $\left(1^{0} \mathrm{C}\right.$ for wheat and maize and $2{ }^{\circ} \mathrm{C}$ for rice) can reduce yields significantly because many crops are already at the limit of their heat tolerance.

Constraints perceived in the adoption of best farm practices for sequestration of greenhouse gases (GHGs): Table 2 results reveled that a significant majority $(96.11 \%)$ of the farmers told that Non - availability of package of practices to reduce GHGs emission is major problem in adoption of farm practices for sequestration of GHGs. More than ninth-tenth $(94.72 \%)$ of farmers told that lack of awareness about health risk in humans perceived as problem among the farmers. Majority $(93.05 \%)$ of the farmers also believed that No reward for adoption of environmental measures given by the government and they perceived as a problem. 91.11 percent of farmer considered that Lack of demonstration/ training for reducing GHGs emission was a major problem in adoption of alternative measures for sequestration of GHGs because they were not able to adopt with any training and demonstration. Farmers believed that less credibility in farm practices that reduce the GHG emission with $(90 \%)$ respondents. Majority $(89.72 \%)$ of the

Table 1. Losses due to greenhouse gases (GHGs) emission $(\mathrm{N}=120)$.

\begin{tabular}{lllll}
\hline S. N. & Losses & $\begin{array}{l}\text { Total weighted } \\
\text { score }\end{array}$ & $\begin{array}{l}\text { Weighted } \\
\text { mean score }\end{array}$ & Z Score \\
\hline 1. & Crop benefit ratio decreased & 335 & 2.79 & 1.23 \\
2. & Crop damaged due to adverse climatic uncertainty & 328 & 2.73 & 1.07 \\
3. & Crop production decreased & 320 & 2.66 & 0.89 \\
4. & Sowing season changed & 314 & 2.65 & 0.86 \\
5. & Loss in biodiversity & 317 & 2.64 & 0.84 \\
6. & Less income from agriculture & 316 & 2.63 & 0.81 \\
7. & Soil water holding capacity decreased & 310 & 2.58 & 0.68 \\
8. & Deeper level of ground water table & 293 & 2.44 & 0.31 \\
9. & Cropping pattern and cropping system changed & 292 & 0.23 \\
10. & High usages of synthetic or inorganic fertilizers & 290 & 2.43 & 0.13 \\
11. & Soil fertility decreased & 285 & 2.41 & 0.10 \\
12. & Degradation of forests to barren lands & 284 & 2.37 & 0.07 \\
13. & Soil erosion & 283 & 2.36 & 0.00 \\
14. & Cropping intensity decreased & 279 & 2.35 & -0.02 \\
15. & Change of land for housing/industrial usage/SEZ & 278 & 2.32 & -0.07 \\
16. & Quality deterioration of crop produce & 275 & 2.31 & -0.13 \\
17. & Crop loss due to flood and drought & 273 & 2.29 & -0.18 \\
18. & Quitting agriculture leads unemployment & 270 & 2.27 & -0.47 \\
19. & Desertification due to prolonged drought & 257 & 2.25 & -0.86 \\
20. & Reduction in soil carbon stocks & 239 & 2.14 & -1.13 \\
21. & Frequent crop failure & 227 & 1.99 & -1.44 \\
22. & Loss in soil organic matter & 213 & 1.89 & 1.77 \\
\hline
\end{tabular}

$\overline{\bar{X}}=2.00$ V S - Very serious; S.D. 0.38; S - Serious; NSS- Not so serious 


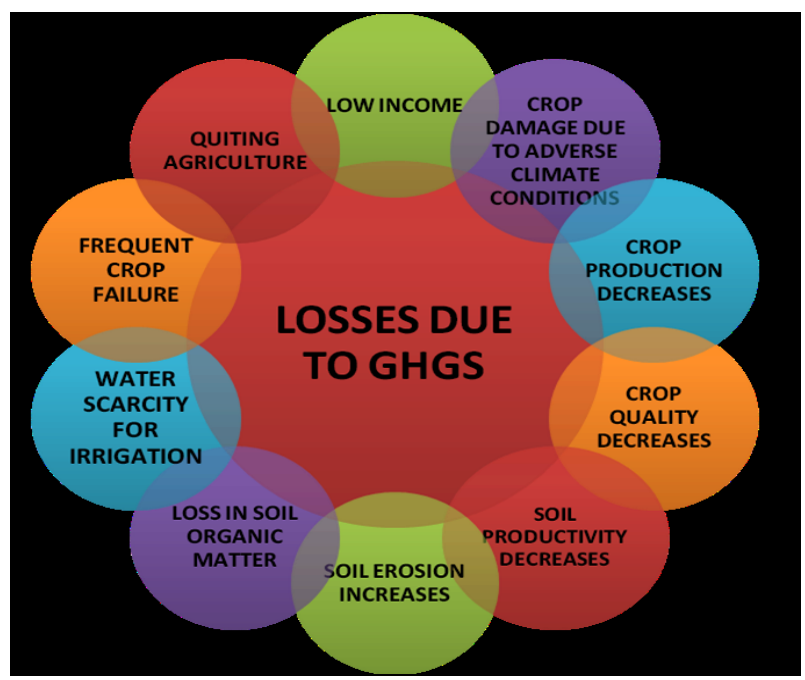

Fig. 1. Major losses due to GHG in agriculture Source: (Mukteshawar, 2013).

farmers considered that Lack of appropriate transfer of technology for sequestration of GHG was a major problem regarding adoption of farm practices.

It is revealed from the table 2 that majority of the respondent $(89.16 \%)$ told that Inadequate training facilities is a major constraint in adoption of farm practices for reduces the GHG emission. More than fourth-fifth $(88.88 \%)$ of the farmers believed that farmers ignore the bed effect of chemical hazardous on health also a major problem for adoption. It was found from the data that $(88.61 \%)$ farmers consider Slow results of ecofriendly practices is also responsible for non - adoption of farm practices.

It is found from table 2 that due to Lack of awareness among the farmers is more $(85.55 \%)$ about environmental degradation. The data analyzed that mostly (84.44\%) farmers burn their crop residue in the field. Lack of collective action for sequestration of GHG was a problem perceived by $(82.50 \%)$ of the farmers. It was revealed that $(81.94 \%)$ respondents found that Lack of training imparting to farmers about sequestration of GHGs considered as a problem for non - adoption of farm practices to sequestration of GHGs for better development in agriculture.

The data in the table 2 revealed that No any special agency provider for promotion of healthy climate activities was considered serious problem in adoption of farm practices by 80.27 percent of the respondents. The data also revealed that Lack of interest to learn new skill in the farmers' also considered as a problem by the (78.33\%) farmers. 77.77 percent of the respondents considered as Lack of linkage for sequestration of GHGs between various organizations was a problem regarding non - adoption of farm practices. Farmers (74.44\%) also believed that Non-adoption of recommended weather measure practices was also a major constraint.

It was revealed from the data that Lack of knowledge of extension functionaries about the farm practices for reducing GHGs emission is also a problem regarding Nonadoption of farm practices according to $(73.61 \%)$ the respondents. Irregular and less predicted weather prediction was also found $(70.55 \%)$ a major problem. It revealed that $(67.50 \%)$ respondents found that Lack of effective communication between field functionaries and farmers considered as a problems.

All other constraints/problems can be minimized by providing guidance to the farmers and training regarding technicality of sequestration of GHGs for sustainable agriculture to the farmers.

Table 2. Factors responsible for non- adoption of best farm practices to reduce the greenhouse gases (GHGs) emission ( $\mathrm{n}=120$ ).

\begin{tabular}{|c|c|c|c|}
\hline S. $\mathbf{N}$. & Non - adoption practices & $\begin{array}{l}\text { Weighted } \\
\text { mean score }\end{array}$ & $\begin{array}{l}\text { Mean } \\
\text { score (\%) } \\
\end{array}$ \\
\hline 1. & Non-availability of package of practices to reduce greenhouse gas emission & 2.88 & 96.11 \\
\hline 2. & Lack of awareness about health risk in humans & 2.84 & 94.72 \\
\hline 3. & No reward for adoption of environmental measures & 2.79 & 93.05 \\
\hline 4. & Lack of demonstration/training for reducing GHG emission & 2.73 & 91.11 \\
\hline 5. & Less credibility in farm practices that reduce the GHG emission & 2.70 & 90.00 \\
\hline 6. & Lack of appropriate transfer of technology for sequestration of green house gases & 2.69 & 89.72 \\
\hline 7. & Inadequate training facilities for reduce $\mathrm{GHG}$ emission & 2.69 & 89.16 \\
\hline 8. & Ignorant about the bed effect of chemical hazardous on health & 2.66 & 88.88 \\
\hline 9. & Slow results of eco- friendly practices & 2.65 & 88.61 \\
\hline 10 . & Lack of awareness about environmental degradation & 2.56 & 85.55 \\
\hline 11. & Mostly farmers burn crop residue in the fields & 2.53 & 84.44 \\
\hline 12. & Lack of collective action for sequestration of GHG & 2.47 & 82.50 \\
\hline 13. & Lack of training imparting to farmers about sequestration of GHG & 2.45 & 81.94 \\
\hline 14. & No any special agency/provider for promotion of healthy climate activities & 2.40 & 80.27 \\
\hline 15. & Lack of interest to learn skill & 2.35 & 78.33 \\
\hline 16. & Lack of linkage for sequestration of GHG between various organization & 2.33 & 77.77 \\
\hline 17. & Non availability of recommended weather forecasting & 2.23 & 74.44 \\
\hline 18. & $\begin{array}{l}\text { Lack of knowledge of extension functionaries about the farm practices for reducing } \\
\text { GHG emission }\end{array}$ & 2.20 & 73.61 \\
\hline 19. & Irregular and less predicted weather prediction & 2.11 & 70.55 \\
\hline 20. & Lack of effective communication between field functionaries and farmers. & 2.02 & 67.50 \\
\hline
\end{tabular}

Figures in parentheses in column 3 indicates weighted mean scores and column 4 indicates mean score expressed in percentage. 


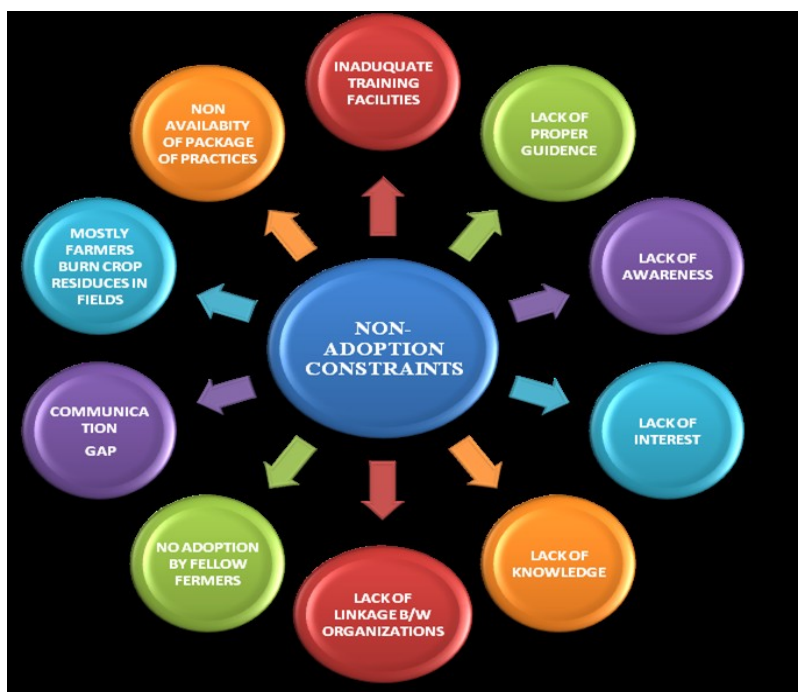

Fig. 2. Problems encountered in adoption of farm practices to reduce the GHGs (Source: (Mukteshawar, 2013)

\section{Conclusion}

Results showed that majority of the farmers had good knowledge towards losses due to GHGs and farmers knew the major constraints, which were found responsible in non-adoption of farming practices towards sequestration of GHGs in agriculture. Due to emissions of GHGs, the agricultural practices were flocculated that because agricultural practices totally depends on whether parameters. Thus, it was clear from this study that sequestration of GHGs will be more readily adopted if the agricultural extension services are improved.

\section{ACKNOWLEDGEMENT}

Authors are extremely thankful to farmers for giving response so that their awareness and perception can be carried out on scale.

\section{REFERENCES}

Aggarwal, P.K. (2008). Global climate change and Indian agri- culture: impacts, adaptation and mitigation. Indian Journal of Agricultural Sciences. 78(11): 911-919.

Aggarwal, P.K. (2003). Impact of climate change on Indian agriculture. J. Plant Biol., 30, 189-198.

Anonymous (2010). Survey on global warming - Report from Kingston High School, Tasmania together http:// www.tasmaniatogeather. tas. gov. au/reports and paper/ document /site documents / Kinston High School Global Warming.pdf.open document retrieved on 21 May 2010.

Attri, S.D. and Rathore, L.S. (2003). Simulation of Impacts of Projected Climate Change on Wheat in India. International Journal of Climatology, 23 (6): 693 - 705.

IPCC (2001). Climate change: Impacts, Adaptation and Vulnerability. Intergovernmental Panel on Climate Change . Cambridge Uni. Press, Cambridge, UK.

IPCC. (2006). IPCC Guidelines for National Greenhouse Gas Inventories. Agriculture, Forestry and Other Land Use.Vol.4: Chapter1-12.

Katyal, J.C. (2000). Organic matter: mainstay of soil quality. $J$. Indian Soc. Soil sci., 48:704-716.

Ladha, J.K., Hill, J.E., Duxbury, J.M., Gupta, R.K., Harrington, L.W. (Eds.), (2003). Improving the productivity and substantiality of rice-wheat systems: issues and impacts. ASA Special Publication No. 65. American Society of Agronomy. p. 231.

Mukteshawar, R. (2013). Losses due to GHG in agriculture. Farmers' awareness and perception towards sequestration of greenhouse gases for sustainable agriculture. M.Sc (Agri), Thesis, CCSHAU, Hisar.

Ramaraj, A.P., Jagnnathan, R. and Dheebakaran, G. (2009). Impact of climate change on rice and groundnut yield using, PRECIS Regional Climate Model and DSSET crop simulation model. ISPRS Archives XXXVIII-8/W3 Workshop Proceedings: Impact of Climate Change on Agriculture. ISPRS Ahmedabad, Space Applications Centre (ISRO):17-18.

Rosegrant, M. Yohe, G.; Ewing, M.; Valmonte-Santos, R.; Zhu, T.J. Burton, I. Huq, S. (2010). Climate change and Asian agriculture. Asian Journal of Agriculture and Development. 7(1):41-82.

Sinha, S.K., Singh, G.B. and Rai, M. 1998. Decline in crop productivity in Haryana and Punjab: myth or reality? Indian Council of Agricultural Research, New Delhi 89 pp. 